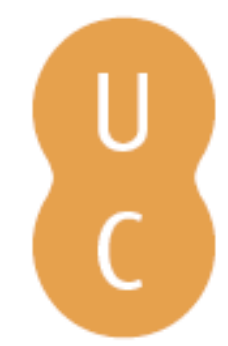

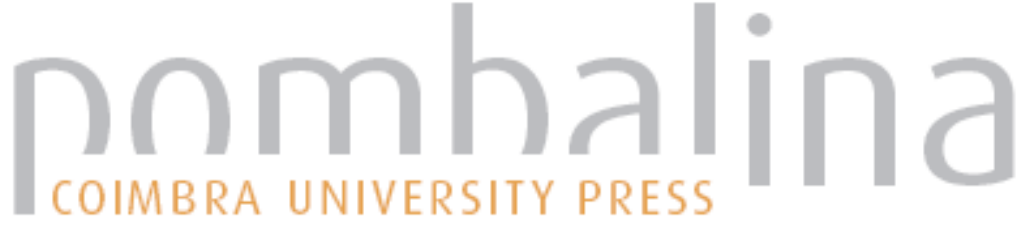

\section{Mitos de fundação de cidades e a representação do espaço urbano nas Metamorphoses de Ovídio}
Autor(es): $\quad$ Cabeceiras, Manuel Rolph de Viveiros
Publicado por: Associação Portuguesa de Estudos Clássicos; Imprensa da
URL persistente: Universidade de Coimbra
DOI:
URI:http://hdl.handle.net/10316.2/31773
DOI:http://dx.doi.org/10.14195/978-989-721-069-3_20
Accessed : $\quad$ 26-Apr-2023 06:19:20

A navegação consulta e descarregamento dos títulos inseridos nas Bibliotecas Digitais UC Digitalis, UC Pombalina e UC Impactum, pressupõem a aceitação plena e sem reservas dos Termos e Condições de Uso destas Bibliotecas Digitais, disponíveis em https://digitalis.uc.pt/pt-pt/termos.

Conforme exposto nos referidos Termos e Condições de Uso, o descarregamento de títulos de acesso restrito requer uma licença válida de autorização devendo o utilizador aceder ao(s) documento(s) a partir de um endereço de IP da instituição detentora da supramencionada licença.

Ao utilizador é apenas permitido o descarregamento para uso pessoal, pelo que o emprego do(s) título(s) descarregado(s) para outro fim, designadamente comercial, carece de autorização do respetivo autor ou editor da obra.

Na medida em que todas as obras da UC Digitalis se encontram protegidas pelo Código do Direito de Autor e Direitos Conexos e demais legislação aplicável, toda a cópia, parcial ou total, deste documento, nos casos em que é legalmente admitida, deverá conter ou fazer-se acompanhar por este aviso.

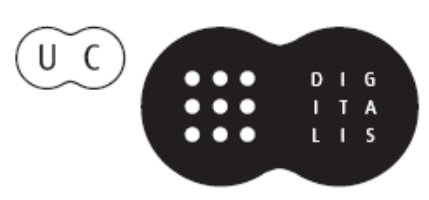




\section{Espaços e Paisagens}

\section{Antiguidade Clássica e Heranças Contemporâneas}

Vol. I Línguas e Literaturas. Grécia e Roma

Francisco de Oliveira, Cláudia Teixeira, Paula Barata Dias (coords.)

IMPRENSA DA UNIVERSIDADE DE COIMBRA 


\title{
MITOS DE FUNDAÇÃO DE CIDADES E A REPRESENTAÇÃO DO ESPACO URBANO NAS METAMORPHOSES DE OVIÍDIO
}

\author{
Manuel Rolph De Viveiros Cabeceiras \\ Universidade Federal Fluminense \\ Rio de Janeiro
}

\begin{abstract}
In the founding myths of the city the Ancients report how they understand the inaugural act of demarcation of the urban space, and through it, their own relationship with the cosmos. Inside their limits not only the field and the city are represented, but the own identity of the people. These are central questions in the Rome of Augustus, new Romulus, and the way they are treated in the Ovid's Metamorphoses is our purpose in this paper.
\end{abstract}

Keywords: Ancient Rome, Augustan Era: poetry, imaginary, mythology, urban space.

Palavras-Chave: Roma Antiga. Século de Augusto: poesia, espaço urbano, imaginário, mitologia.

Inúmeras cidades se sucedem nos relatos de Ovídio em Metamorphoses Libri $X V$. Destacam-se as menções a Tiro, Tebas, Argos, Esparta, Micenas, Tróia, Atenas e, entre todas, presente mesmo quando não citada, a maior, Roma.

No entanto, ao leitor da Ars Amatoria e do Remedia Amoris, a surpresa: se nelas os comentários às mais diversas situações oportunizam "flashes" de uma gama variada de práticas e paisagens urbanas, já em Metamorphoses pouco ou nada desse urbano frescor cotidiano das citadas elegias sobrevive.

Objeto de descrição mais detalhada, no épico ovidiano, são as florestas e campos, grutas e praias. Tal como a Arcádia (um eco das Eclogae de Virgílio?) tida por Júpiter após o desastre de Faetonte como a sua maior preocupação e então nos transmite uma vívida imagem, apesar de curta, da reconstrução da área pelo soberano deus ${ }^{1}$.

Para um poeta como Ovídio, riquíssimo na construção dos mais variados painéis, não se acha ao longo do poema quase detalhe algum a respeito do cenário e dos aparelhos urbanos. Não fosse a menção de "as grandes cidades e também suas muralhas; as nações perecem com toda a sua população: tudo vira cinzas" ${ }^{2}$, seria legítimo imaginar não existirem estruturas urbanas quando

1 2.401-408: "At pater omnipotens ingentia moenia caeli / circuit et ne quid labefactum uiribis ignis / corruat, explorat. quae postquam firma suique / roboris esse uidet, terras hominumque labores / perspicit. Arcadiae tamen est inpensior illi / cura suae: fontesque et nondum audentia labi / flumina restituit, dat terrae gramina, frondes / arboribus, laesasque iubet reuirescere siluas".

2 2.214-216a: "Parua queror: magnae pereunt cum moenibus urbes, / cumque suis totas populis 
da solar aventura faetôntica. É bem verdade, há uma alusão anterior, mas única, en passant, e tratada como elemento da paisagem natural, ao citar como submersos pelo dilúvio, as "casas, cidades, parques, bosques" ${ }^{3}$.

Há, entretanto, nos primeiros versos, uma imagem a trair, em nossa opinião, nítida inspiração citadina: movido pela enormidade do sacrilégio do selvagem rei Licaão, Júpiter convoca todos os deuses para uma assembléia ${ }^{4}$, e essa vem a se reunir no Palatino, não no Olimpo, transmitindo-nos a idéia dos deuses viverem em uma Roma antes de Roma, pré-figuração da "capital do mundo" 5. E aqui se acha a grande característica das cidades em Metamorphoses: a sua afirmação política. A mais evidente marca das cidades são os templos, apesar delas prescindirem e se acharem em qualquer sítio, onipresentes como um canto a pietas a ressoar por todo o poema. É fato, inexistem cidades sem templos e muralhas e, por isso, colocadas sob o império da lei, fornecem proteção e segurança.

Cidade e segurança, um binômio cuja pertinência para a cidade de Roma, dado o seu desmesurado crescimento, vinha sendo posto em questão desde os fins da República. Daí a evasão imagética para um campo cada vez mais idílico, do qual a já citada Arcádia vai se tornando a grande expressão. Todavia o binômio faz morada renitente no imaginário mediterrânico. Assim, fora da "cidade murada de tijolos", a Babilônia da rainha Semíramis ${ }^{6}$, dois jovens apaixonados, Píramo e Tisbe, se arriscam noturnamente em um encontro furtivo e acabam vítimas da instável mistura de seus temores além-muros mais audácia e enganos que se faz letal diante da chegada precoce e casual de uma leoa ao local marcado.

Para além das florestas e campos, grutas e praias, Ovídio percorre também os céus e a intimidade do lar, imerge nos bosques e nas regiões infernais, tudo é cenário para as façanhas narradas. Nada ocorre, porém, nas praças e nas ruas, no espaço público da ordenada vida urbana. Quando essas são mencionadas o são enquanto lugares de ordem, da afirmação do poder e da soberania. Não há neles espaço para a desordem.

A única exceção são os templos, o que é típico, pois sendo públicos e os mais privilegiados espaços da ordem, se revelam como os mais indicados espaços da contestação, alvos de personagens dominados por uma insana "desmedida". Contudo, a pressurosa punição que se lhes acarreta tal atitude não é, porém, concedida, no mesmo lugar do desafio. Quando Níobe, p. ex., desafia Latona,

incendia gentis / in cinerem uertunt; (...)".

3 1.301-303: "Mirantur sub aqua lucos urbesque domosque / Nereides siluasque tenent delphines et altis / Incursant ramis agitataque robora pulsant".

${ }^{4}$ 1.164-167: "Ingenit et, facto nondum uulgata recenti / Foeda Lycaoniae referens conuiuia mensae, / Ingentes animo et digna Ioue concipit iras / Conciliumque uoct; tenuit mora nulla uocatos".

5 1.170-180: "Hac iter est superis ad magni tecta Tonantis / regalemque domum: dextra laeuaque deorum / atria nobilium ualuis celebrantur apertis. / plebs habitat diuersa locis: hac parte potentes / caelicolae clarique suos posuere penates; / hic locus est, quem, siu uerbis audacia detur, / haud timeam magni dixisse Palatia caeli. / Ergo ubi marmoreo superi sedere recessu, / celsior ipse loco sceptroque innixus eburno / terrificam capitis concussit terque quaterque / caesariem, cum qua terram, mare, sidera mouit".

6 4.57b-58: “(...) ubi dicitur altam/coctilibus muris cinxisse Semiramis urbem”. 
mãe de Apolo e Diana, no seu próprio templo, é fora das muralhas de Tebas que seus filhos e filhas, e ela própria, perecerão, por sua soberba presunção, em castigo (6.146-390).

Também a recompensa por uma adequada e satisfatória atitude devota, expressa no templo em justas oração e oferenda, nele não tem lugar, embora ocorra a sua satisfação no intramuros. Esse é o caso de Pigmalião (10.243297), cuja revolta pelos vícios das mulheres o levara a delas se afastar e, hábil artesão, a esculpir aquela que seria a mulher ideal. Devoto de Vênus lhe dirigiu humildes preces e quando menos esperava, em verdade imediatamente, tão convenientes foram a sua postura e atitude, é atendido.

A contraposição entre a ordem da cidade e a desordem quando se ausentam os valores que lhe fundamentam (pietas, iustitia, pax, concordia) é também patene no confronto entre os bordados de Minerva e Aracne. Em Minerva (6.70-102) vemos o Areópago, colina sagrada de Atenas, os doze olímpicos em seus tronos, as ofertas de Netuno e da própria Minerva à recém-fundada cidade que tomará da deusa o nome (Atenas de Atena, o nome helênico da deusa), acrescentando ao conjunto, nos quatro cantos do bordado, as punições a quem ousara desafiar os deuses, emoldurando tudo com ramos de oliveira, remissão clara à cidade e à deusa. Já em Aracne (6.103-128), os deuses são mostrados como enganadores e a ofensa é multiplicada em inúmeros quadros numa sucessão inebriante de desafios, sem qualquer princípio ordenador além da manifesta disposição soberba de contenda num franco desafio à harmonia cósmica.

O disciplinamento do espaço e a sua demarcação são atos fundadores da cidade e a sintonizam com o cosmos. Ao universo, por definição, é inerente a ordem. Roma e sua civilização se confundem com a presença da urbanidade. O seu domínio se estende e se consolida com a ampliação da rede citadina. Todavia, é preciso esclarecer, o modo romano de se fazer cidade implica duas faces: cidade se diz ciuitas e se diz urbe, possui uma dimensão cívica, enquanto conjunto de cidadãos, expressão de uma comunidade legiferante, e possui uma dimensão espacial, da qual não está ausente a integração entre a área urbana e a rural, por mais que a maior parte das pessoas residam nesta última área.

Tal associação se acha bem delineada no mais minucioso mito de fundação nas Metamorphoses inscrito. Trata-se do mito de fundação de Tebas por Cadmo (3.1-137). Cadmo é um herói pius. Por obediência ao pai, Agenor, rei de Tiro, na Fenícia, parte em busca da irmã Europa sem saber que esta havia sido raptada por Júpiter. Não obstante, como o pai proibira o seu retorno à pátria sem a irmã, ao perceber como um desígnio divino o arrebatamento da irmã, procura conselho junto ao oráculo de Apolo, cuja orientação segue à risca: procura e encontra a novilha que nunca usara canga e a segue até o lugar de seu destino, o qual entenderá como sendo também o local a si reservado pra se fixar.

Pois bem, o re-ordenamento que a fundação de uma cidade exige implica em atos de purificação. A busca de água para a libação a Júpiter o leva a enfrentar uma serpente, a qual vence. Da semeadura dos dentes do réptil, 
seguindo orientação divina, após abrir profundos sulcos na terra, surgem-lhe os companheiros com os quais vem a fundar Tebas. Demarcação de espaços, agricultura e pecuária, leis, tudo aqui é mostrado.

O vínculo campo-cidade também é frisado na apresentação da deusa Ceres, "a primeira a rasgar a terra com a relha do arado, a primeira a dar às terras frutos e alimentos maduros. A primeira a dar as leis; tudo é dádiva de Ceres" 7 . Outrossim, Enéias, saído de Tróia incendiada, ao buscar o conselho de Apolo em Delos, a cidade é descrita em seus santuários e nas duas árvores tornadas sagradas por Latona nas dores do parto ${ }^{8}$. Não se pode deixar de mencionar que o mito de Cadmo, na rede de significações construída na narrativa ovidiana, remete justa e estruturalmente ao mito de Enéias.

É nossa hipótese que Metamorphoseon Libri $X V$ apresenta uma estrutura redacional quiasmática ${ }^{9}$, fazendo o livro I remeter ao XV, o II ao XIV, o III ao XIII e assim por diante, valendo também o caminho inverso em cada par (XV ao I etc), estabelecendo a cada vez a sua própria relação, seja de complementação, oposição, duplicação, ampliação ou várias delas simultaneamente. Assim, ao mito de fundação de Tebas (livro III) se contrapõe a narrativa da queda e destruição de Tróia (livro XIII), promovendo de tal sorte a entrada em cena de Enéias, paradigma para os romanos de herói pius.

E ainda, só para nos limitarmos a alguns exemplos: à ofensa sacrílega de Licaão (livro I) uma outra ao matarem César enquanto Pontífice Máximo (15.745-870) e se, como mostramos, Roma era prefigurada no livro I, no XV se afirma o império e a pax de Roma, presentificada como cidade universal, sobre todo o orbe. Ali o Palatino, aqui o Capitólio. Lá Júpiter convocou os deuses e eles foram a ele, aqui uma deusa, Vênus, vai aos deuses todos e, por fim, chega em Júpiter, solicitando intervenção. Lá a intervenção ocorre, aqui não há como ocorrer, ambas as deliberações são perenni fata, o que não impede do universo inteiro, como lá, se comover. O fatum, o destino, em ambos, uma progressão justa, em prol do ordenamento cósmico, daí o sucessor ser maior que o antecessor: antes, Júpiter sucedia Saturno, agora César deve partir, favorecendo a sua própria deificação e a ascensão de Augusto, o qual como Júpiter, assumirá o seu lugar no universo, trazendo paz e justiça ao mundo e à

7 5.341-343: "Prima Ceres unco glaebam dimovit aratro, / prima dedit fruges alimentaque mitia terris, / prima dedit leges; Cereris sunt omnia munus".

8 13.633b-635: “(...) temploque domoque recepit / urbemque ostendit delubraque nota duasque/ Latona quondam stirpes pariente retentas".

${ }^{9}$ Em Viarre 1976: 89-91, Crabbe 1981 e Solodow 1988: 9-36, p. ex., podem ser achados levantamentos a respeito das pesquisas desenvolvidas no afã de se buscar uma leitura estrutural para as Metamorphoses de Ovídio. Entre tais autores cabe destacar: Grimal (apud Herescu 1958: 245-257), resgatando a coerência cronológica dos mitos nela narrados, através da qual seriam fixados os ciclos em torno de uma determinada personagem ou família; Myers 1994, ao propor, a partir de um minucioso estudo das etiologias trabalhadas, um enquadramento filosófico pitagórico; e Otis 1966, que divide a obra em quatro grandes seções, sem afetar a continuidade entre uma seção e outra, mas que estaria, cada uma, no respeitante aos temas, organizada segundo a lógica de um quiasmo. A idéia, entretanto, desse quiasmo abranger, como princípio de inteligibilidade, a obra por inteiro, sugeriu-nos Mendes 1985, ao propor tal estrutura para explicar a arquitetura das Eclogae virgilianas. 
cidade, urbi et orbi, arremate do ciclo de narrativas cantadas pelo poeta e, com a sua chancela, tornadas imperecíveis (15.871-879).

\section{Bibliografia}

\section{Fontes}

Ovídio. Les Métamorphoses (trad. Gustave Lafaye). Paris: Belles Lettres, 19851989.

. Metamorfosis (trad. Ruben Bonifaz Nuño). Mexico: Universidad Nacional Autónoma de Mexico, 1980. - As Metamorfoses (trad. David Gomes Jardim Jr.). Rio de Janeiro: EdiOuro, 1983. . As Metamorfoses I - V(trad. Antônio Feliciano de Castilho). Rio de Janeiro: Simões, 1959. . Extraits de Métamorphoses (ed. H. Martin). Paris: Hachette, 1930. Metamorphoses I (ed. A. G. Lee). Wauconda: Bolchazy-Carducci, 1988. 1981.

Metamorphoses III (ed. A. A. Henderson). Bristol: Bristol Classical,

\section{Estudos}

A. Crabbe (1981), "Structure and Content in Ovid's 'Metamorphoses", in Temporini Und Haase (hrsg.), ANRN: Geschichte und Kultur Roms im Spiegel d. neueren Forschung, Berlin/ New York, Walter de Gruyter \& Co.,.

N. I. Herescu (org.). (1958), Ovidiana. Recherches sur Ovide. Paris, Belles Lettres.

J. P. Mendes (1985), Construção e arte das Bucólicas' de Virgílio. Brasília: EdUnB.

K. S. Myers (1994), Ovid's causes. Cosmogony and aetiology in the 'Metamorphoses'. Ann Arbor: Univ. of Michigan Press.

B. Otis (1966), Ovid as an Epic Poet. Cambridge, Univ. Press, 1966.

J. B. Solodow (1988), The world of Ovid's 'Metamorphoses'. Chapel Hill: Univ. of Carolina Press.

S. Viarre (1976), Ovide. Essai de lecture poétique. Paris, Belles Lettres. 